health action steps is challenging. Clinicians need more training in motivational counseling to influence adolescents. Adolescent-appropriate informational materials and referrals also need to be available. With further development, this innovative health screener could be an attractive tool for clinicians wanting to improve the adolescent health care they provide.

To read or post commentaries in response to this article, see it online at http://www.annfammed.org/cgi/content/full/3/Suppl_2/S63.

Key words: Primary health care; adolescents; health behavior; practicebased research network; behavioral/psychosocial; teenagers; computers, handheld

Submitted December 20, 2004; submitted, revised, February 22, 2005; accepted March 16, 2005.
Funding support: This project was supported by Prescription for Health, a national program of The Robert Wood Johnson Foundation with support from the Agency for Healthcare Research and Quality.

Acknowledgments: We would like to acknowledge our participating practices: The Bedford and Plymouth regional pediatric practices of Dartmouth-Hitchcock Medical Center in Lebanon, NH, Exeter Pediatric Associates in Exeter, NH, Abenaki Family Physicians in Wolfeboro Falls, NH, and Evergreen Family Health in Williston, Vt. Thanks to Cheryl Bush for her administrative expertise.

\section{References}

1. Klein JD, Wilson KN. Delivering quality care: adolescents' discussion of health risks with their providers. J Adolesc Health. 2002;30:190-195.

2. Elster AB, Kuznets NJ, eds. AMA Guidelines for Adolescent Preventive Services: Recommendations and Rationale. Baltimore, Md: Williams and Wilkins; 1994.

\title{
Modular Lifestyle Intervention Tool: A Handheld Tool to Assist Clinicians in Providing Patient-Tailored Counseling
}

Steven W. Heim, MD, MSPH ${ }_{i}{ }^{1,3}$ Moban Nadkarni, $M D_{i}{ }^{2}$ Lisa K. Rollins, $P b D_{i}{ }^{1}$ Jobn B. Schorling, $M D_{i}{ }^{2}$ David B. Waters, $P b D_{i}{ }^{1}$

Fern R. Hauck, MD, MS ${ }_{i}{ }^{1}$ Scott M. Strayer, MD, MPH $H^{1,3}$

${ }^{1}$ Department of Family Medicine, University of Virginia Health System, Charlottesville, Va

${ }^{2}$ Department of Internal Medicine, University of Virginia Health System, Charlottesville, Va

${ }^{3}$ Department of Health Evaluation Sciences, University of Virginia Health System, Charlottesville, Va

Ann Fam Med 2005;3(Suppl 2):S65-S67. DOI: 10.1370/afm.360.

Conflicts of interest: none reported

CORRESPONDING AUTHOR

Steven W. Heim, MD, MSPH, Department of Family Medicine, University of Virginia Health System, PO Box 800729, Charlottesville, VA 22908-0729, heims@virginia.edu

\section{PURPOSE}

A lthough proven health promotion interventions exist for effecting health behavior change, most physicians rarely go beyond simple advice or education when discussing health risk behaviors. ${ }^{1}$ The primary goal of our project was to develop and assess the effectiveness of a handheld computer clinical decision support tool, the Modular Lifestyle Intervention Tool (MLIT). The MLIT was designed to improve clinicians' ability to provide patient-tailored counseling at the point of care regarding tobacco use and unhealthy diet as it contributes to obesity and overweight.

\section{METHODS}

We created the MLIT by convening a multidisciplinary software development group (SDG) that included a family medicine researcher with experience in obesity, 2 general internists with expertise in smoking cessation and motivational interviewing (MI), and a clinical psychologist with expertise in MI. The group successfully adapted 2 clinical guidelines (the Public Health Service's Clinical Practice Guideline for Treating Tobacco Use and Dependence ${ }^{1}$ and the National Heart, Lung, and Blood Institute's Obesity Education Initiative $^{2}$ ) and the behavioral health theories of the 5 $A^{\prime} \mathrm{s}^{3}{ }^{3}$ the stages of change, ${ }^{4}$ and $\mathrm{MI}^{5}$ into a logical and navigable format. The SDG used an iterative process, meeting weekly for approximately 12, 1-hour sessions. The physical layout of the MLIT was represented using Microsoft PowerPoint (Microsoft Corp, Redmond, Wash), which visually simulated the spatial limitations of a handheld computer screen. Hypertext links within this program were used to simulate the navigation between screens on a handheld computer. Professional 
programmers designed the software for both Windows CE and Palm platforms.

The SDG developed a theoretical framework that integrated the $5 \mathrm{~A}^{\prime} \mathrm{s}$, stages of change, and MI (Figure 1). Using the traditional $5 A^{\prime}$ s, the ask component was operationalized by encouraging practices to adopt smoking status and body mass index as vital signs. This approach was designed to prompt physicians to ask about smoking and weight loss, but was not included in the MLIT software. The advise component was integrated into the tool by including information on MI that would facilitate nonconfrontational advice from physicians. The assess and assist components were operationalized using the stages of change theory. The MLIT uses 2 questions on 1 screen to guide the identification (assessment) of the patient's current stage of change, then directs the clinician to assist by providing a stagedbased multidimensional course of action to effect behavior change. For example, for a clinical encounter with a patient who smokes and is considering quitting in the next 6 months, but not within the next 30 days, the MLIT assessment screen automatically informs the clinician that the patient is in the contemplation stage of change and lists stage-appropriate interventions. Each stage is linked to an MI script and stage-relevant clinical content. The scripted MI uses the DARES approach: developing discrepancy, avoiding argumentation, rolling with resistance, expressing empathy, and supporting self-efficacy. ${ }^{5}$ For this patient, the MLIT recommends that the physician explore the decisional balance with the patient and support the patient's selfefficacy in his or her quit attempt. The MLIT prompts the clinician to arrange follow-up and provides a list of both local and national resources

We used a pretest-posttest design to evaluate the effects of the MLIT in a group of academic physicians. The primary outcomes were physician knowledge, behavior, and perceived self-efficacy and comfort in applying effective behavioral counseling techniques before and after use of the tool. We also conducted focus groups at the study's conclusion to better understand how the tool was used, barriers to its use, and how the tool could be improved.

\section{LESSONS LEARNED}

Many clinicians, even computer-savvy ones, needed the research team to install the MLIT software. Numerous technological barriers were unanticipated, including our institution's network firewall, the variety of older handheld computers still in use, and the inability of many clinicians to synchronize their handheld computer to
Figure 1 . Integrating the behavioral theories.

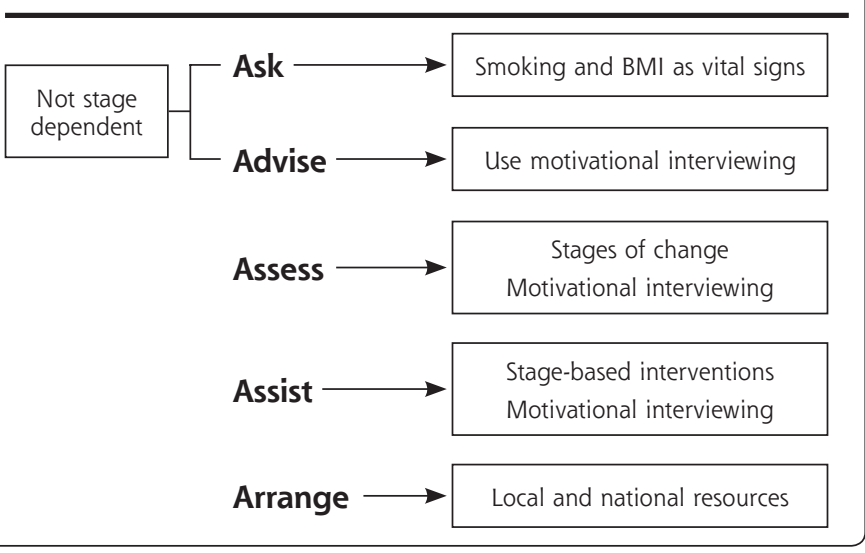

their desktop computer (because of institutional security precautions). These barriers required that our study coordinator spend more time with each clinician than originally planned. We used this unanticipated contact to provide project education and support. Busy clinicians, particularly novice handheld computer users, needed encouragement to use the MLIT in the setting of a patient-doctor clinical interaction. First impressions were critical. It was very difficult to overcome resistance to using the program after a clinician had initial problems with the technology.

Using an SDG composed of local content experts to develop the MLIT was successful and efficient. Members of the group understood the competing demands of primary care, were supportive of the project's underlying premise, and were able to distill complex guidelines and behavioral theories into a simple, easy-to-use tool for use at the point of care. One author (SMS) had experience with developing software and adapting clinical guidelines for use on handheld computers. ${ }^{6}$ Having content experts meet with a physician who is competent in software development is essential for the group to understand the capabilities and limitations of the software (eg, the need to minimize complexity to reduce program size) and hardware (eg, the need to minimize text because of small screen size). This physician also met frequently with the programmers to ensure the feasibility of the tool as envisioned by the SDG. Early iterations of the MLIT were demonstrated and evaluated by both the SDG and the research team using Microsoft PowerPoint in group settings. This approach allowed real-time mock use of the tool through role-playing scenarios and is the subject of a future paper. Through this process, we believed that a similar approach might be successful in adapting clinical guidelines for any type of computer system (eg, electronic medical records, Web-based systems) to support clinicians at the point of care. 
Originally conceived as a clinical decision support tool, the MLIT is better framed as "continuing medical education (CME) on the fly." Adult learning principles suggest that adults learn best on a need-to-know basis in real-time, hands-on experiential settings. ${ }^{7}$ The MLIT allows the user to acquire knowledge of complex behavioral change theory at the point of care through the provision of targeted and scripted language specific to the patient's stage of change. As physicians internalize the MLIT approach to behavior change counseling, they will have less need to use the tool. The MLIT content can be changed to match physicians' CME needs.

\section{CONCLUSIONS}

It is possible to design innovative, dynamic, and accessible tools that can improve the delivery of effective patient-tailored counseling using handheld computers. These tools are probably best developed and evaluated by primary care physicians and researchers with the support of software programmers. This combination better ensures the development of clinical decision support tools that are useful and practical. Our study illustrates a successful collaborative development process that can be replicated in other settings. Designing and implementing innovative information technology solutions to clinical problems is fraught with technological hurdles. Even computer-savvy clinicians require faceto-face instruction, structured orientation, and direct encouragement, combined with ongoing feedback, to overcome initial resistance to incorporating new tools and paradigms into clinical care. Physicians can use these tools to assist behavioral change efforts, and may also acquire new knowledge in the process, indicating a potential use for delivering CME at the point of care. We have developed and are validating a pretest and posttest to measure this acquisition of new knowledge and increases in physicians' perceived self-efficacy in effecting behavior change.
To read or post commentaries in response to this article, see it online at http://www.annfammed.org/cgi/content/full/3/Suppl_2/S65.

Key words: Computers, handheld; clinical decision support; motivational interviewing; smoking cessation; obesity

Submitted December 17, 2004; submitted, revised, March 29, 2005; accepted March 31, 2005.

Funding support: This project was supported by Prescription for Health, a national program of The Robert Wood Johnson Foundation with support from the Agency for Healthcare Research and Quality.

Acknowledgments: We acknowledge Marit Kington, Lynn Seuffert, and Beverly Turner for their assistance with this study. We particularly thank Siddharth Dalal and the Medical Automation Research Center at the University of Virginia for their expertise in software programming. We extend additional thanks to the physician participants in the Departments of Family Medicine and General Internal Medicine at the University of Virginia Health System.

\section{References}

1. Fiore MC, Bailey WC, Cohen SJ, et al. Treating Tobacco Use and Dependence: Clinical Practice Guideline. Rockville, Md: US Department of Health and Human Services; 2000.

2. NHLBI Obesity Education Initiative Expert Panel. Clinical Guidelines on the Identification, Evaluation, and Treatment of Overweight and Obesity in Adults. Rockville, Md: US Department of Health and Human Services; National Heart, Lung, and Blood Institute; 1998. NIH publication 98-4083

3. Whitlock EP, Orleans CT, Pender N, Allan J. Evaluating primary care behavioral counseling interventions: an evidence-based approach. Am J Prev Med. 2002;22:267-284.

4. Prochaska JO, DiClemente CC. Stages and processes of self-change of smoking: toward an integrative model of change. J Consult Clin Psychol. 1983;51:390-395.

5. Miller WR, Rollnick S. Motivational Interviewing: Preparing People for Change. 2nd ed. New York, NY: Guilford Press; 2002.

6. Strayer SM, Martindale JR, Stephen JL. Physician evaluation of a handheld computer smoking cessation intervention tool. Presented at: 2004 Annual Meeting of the Society for Research on Nicotine and Tobacco. Available at: http://63.84.94.99/srnt/abstract/2004/a/retrieval.lasso. Accessed March 14, 2005.

7. Knowles M. The Adult Learner: A Neglected Species. 2nd ed. Houston, Tex: Gulf Publishing Co; 1978. 